\title{
Does sarcopenia affect postoperative short- and long-term outcomes in patients with lung cancer? - a systematic review and meta-analysis
}

\author{
Yo Kawaguchi, Jun Hanaoka, Yasuhiko Ohshio, Keigo Okamoto, Ryosuke Kaku, Kazuki Hayashi, \\ Takuya Shiratori, Akira Akazawa \\ Division of General Thoracic Surgery, Department of Surgery, Shiga University of Medical Science, Shiga, Japan \\ Contributions: (I) Conception and design: Y Kawaguchi; (II) Administrative support: None; (III) Provision of study materials or patients: None; (IV) \\ Collection and assembly of data: Y Kawaguchi, A Akazawa; (V) Data analysis and interpretation: Y Kawaguchi; (VI) Manuscript writing: All authors; \\ (VII) Final approval of manuscript: All authors. \\ Correspondence to: Dr. Yo Kawaguchi. Tsukinowacho, Seta, Otsu, Shiga 520-2192, Japan. Email: kawaguchi1228@yahoo.co.jp.
}

\begin{abstract}
Background: Lung cancer patients frequently suffer from sarcopenia, and reports on the association of resectable lung cancer and their postoperative outcomes are increasing. Information on whether sarcopenia has any impact on short- and long-term postoperative outcomes in patients surgically treated for nonsmall cell lung cancer remains insufficient. Furthermore, reports vary regarding the pathological stage, surgical procedure, diagnostic tool of sarcopenia, cut-off value, prognosis, and postoperative complications. We believe that sarcopenia assessment should be included as one of the factors which affect the surgical outcomes of lung cancer. Thus, we conducted a review and meta-analysis to ascertain the association between sarcopenia and postoperative outcomes.

Methods: We performed a systematic literature search in PubMed/MEDLINE. Studies included cases defined sarcopenia, received lung cancer surgery, assessed postoperative complications, and prognosis. The pooled odds ratios for survival and postoperative complications, with $95 \%$ confidence intervals, were generated using Review manager 5.3.

Results: A total of ten retrospective studies were eligible for this meta-analysis, including a total of 2,643 non-small cell lung cancer patients. All reviews used skeletal muscle mass as a diagnostic tool for sarcopenia. Sarcopenia was associated with worse survival outcomes and increased postoperative complications in patients with resected lung cancer.

Conclusions: Sarcopenia is an independent risk factor for postoperative death and postoperative complications in patients who have undergone surgery. It is necessary to explore the mechanism of sarcopenia and optimal intervention, such as exercise, nutrition, or drug therapy.
\end{abstract}

Keywords: Sarcopenia; lung cancer; surgery; prognosis; postoperative complications

Submitted Oct 12, 2020. Accepted for publication Dec 31, 2020.

doi: $10.21037 /$ jtd-20-3072

View this article at: http://dx.doi.org/10.21037/jtd-20-3072

\section{Introduction}

Sarcopenia is characterized by progressive and generalized loss of skeletal muscle mass and strength, resulting in physical disability, poor quality of life, and death (1). While often reported in the elderly, loss of muscle mass also occurs in patients suffering from congestive heart failure, chronic obstructive pulmonary disease, chronic renal failure, or cancer (1).

Patients with cancer frequently suffer from sarcopenia (2). Sarcopenia in cancer patients is associated with various physiological and metabolic events, including systemic inflammation and alternations in basal metabolic rate. The 
prognosis depends not only on the cancer's aggressiveness but also on the patient's physical condition. Thus, sarcopenia can predict poor survival in patients with various types of cancers (3-5). Stene et al. showed that up to $71 \%$ of advanced lung cancer patients undergoing palliative chemotherapy suffered from sarcopenia (6) and had poor prognoses. On the other hand, patients who undergo surgery for lung cancer are often at early stages and have good performance status. As a result, the prevalence of sarcopenia is lower in these patients $[9-56 \%(7,8)]$.

Recently, reports focusing on patients with early-stage lung cancers are increasing, and they have analyzed the effect of sarcopenia on postoperative short- and longterm outcomes (7-16). Several of these studies indicate that sarcopenia may be a useful risk assessment tool for postoperative complications as well as a prognostic biomarker. However, reports on several factors such as pathological stage, surgical procedure, diagnostic tool for sarcopenia, and the cut-off value vary. Here, we reviewed these various factors and investigated the ability of sarcopenia to predict postoperative prognosis and complications in lung cancer patients. We present the following article in accordance with the PRISMA reporting checklist (available at http://dx.doi.org/10.21037/jtd-20-3072).

\section{Methods}

\section{Literature research and study selection}

We performed a systematic literature search in Medline via PubMed (155 hits) on March 1, 2020. No language restrictions and no filters were applied to the search. The search was performed using the following Mesh terms: "sarcopenia" and "lung neoplasm", "pulmonary neoplasms", "non-small cell lung cancer", and "lung carcinoma". The abstracts identified by the literature search were screened using our inclusion and exclusion criteria. If an abstract was judged as potentially relevant, the full text of the publication was screened. Selected studies were those that included the following contents: (I) sarcopenia assessed by diagnostic tools such as DEXA, BIA, or computed tomography (CT), (II) patients received surgery for lung cancer, (III) shortterm outcomes (postoperative complications) or long-term outcomes [overall survival (OS), disease-free survival (DFS)], and (IV) comparing the survival of patients with sarcopenia and those without sarcopenia. Studies excluded were those that included the following content: (I) patients with small cell carcinoma, and (II) papers other than the original article. This study did not include experimentation on human or animal subjects; thus, institutional review board approval was not required.

\section{Data extraction and quality assessment}

Two authors independently reviewed the extracted information. We obtained clinical data of patients, pathological stages, surgical procedures, diagnostic tools of sarcopenia, cut off values, OS, DFS, postoperative complications and smoking history. If there was a discrepancy, the authors discussed and resolved it.

Since the meta-analysis was based on observational studies, we used the Newcastle-Ottawa Scale (NOS) as previously used (17), which consists of three factors: patient selection, comparability of the study groups, and assessment of outcomes, to assess the quality and risk-of-bias analysis of observational studies. We assigned a score of 0-9 (9 is the highest quality) to each observational study (Table 1).

\section{Statistical analysis}

A meta-analysis was performed for perioperative complications rate and survival using Review manager version 5.3 (The Nordic Cochrane Center, Copenhagen, Denmark). Heterogeneity was assessed using $\mathrm{I}^{2}$ statistics for describing the proportion of the variability of the observed effect estimates that is caused by the heterogeneity of studies rather than sampling error. Two-sided $\mathrm{P}$ values $<0.05$ were considered statistically significant.

\section{Results}

\section{Search results and characteristics of included studies}

A flow chart of our search results is shown in Figure 1. A total of 155 articles were found in the initial research. We found 13 articles for detailed evaluation. However, some of those papers were later excluded because there was no information on survival. Finally, a total of ten retrospective studies on long-term outcomes (7-16), and six studies on short-term outcomes $(8-11,13,14)$ were included.

Patients' characteristics and surgical details are shown in Table 1. All studies included were single institutional retrospective studies published from 2016 to 2020. The total number of patients included in this review was 2,643 patients, with the number of patients in the reviewed articles ranging from 69 to 556 patients. Although the 


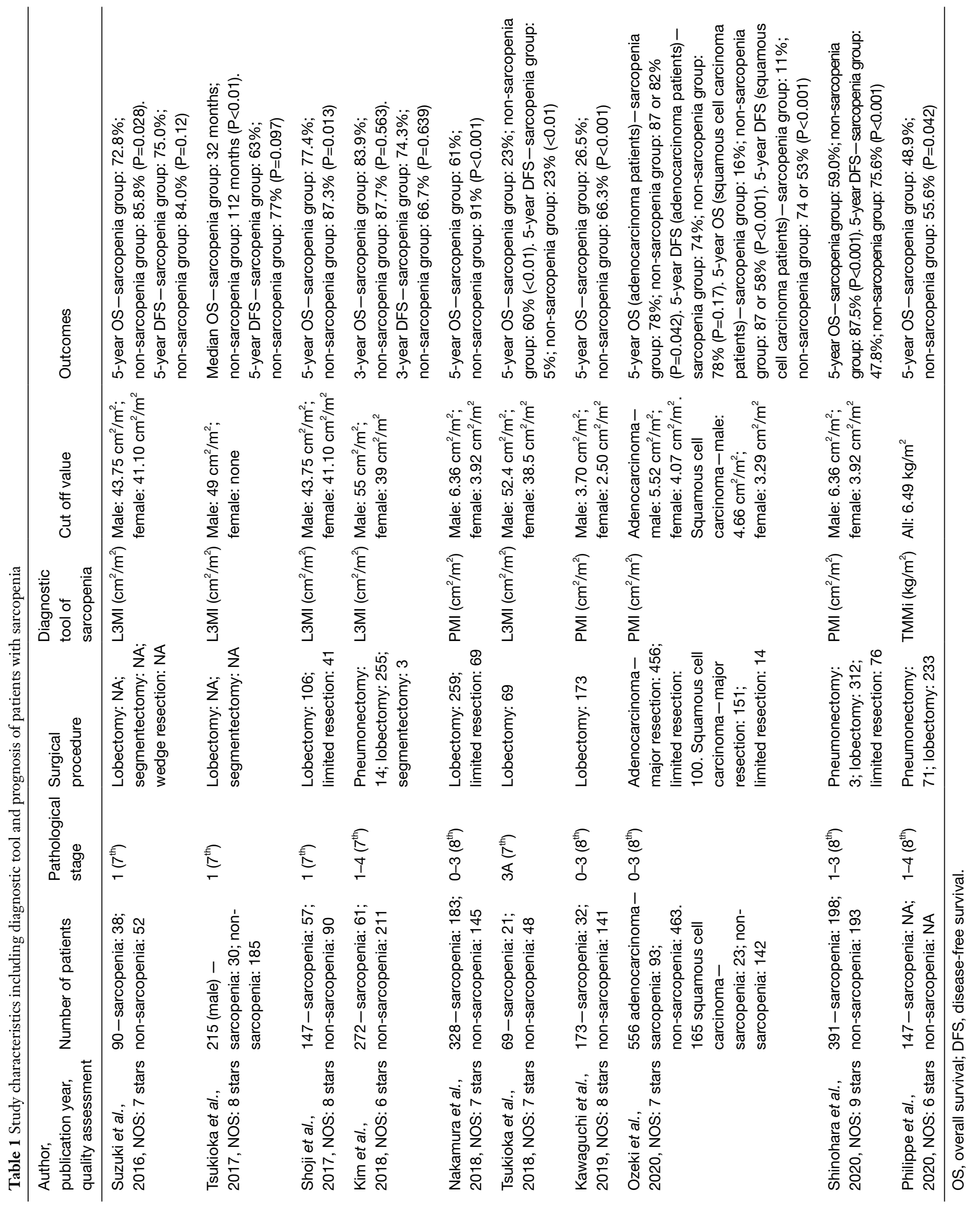




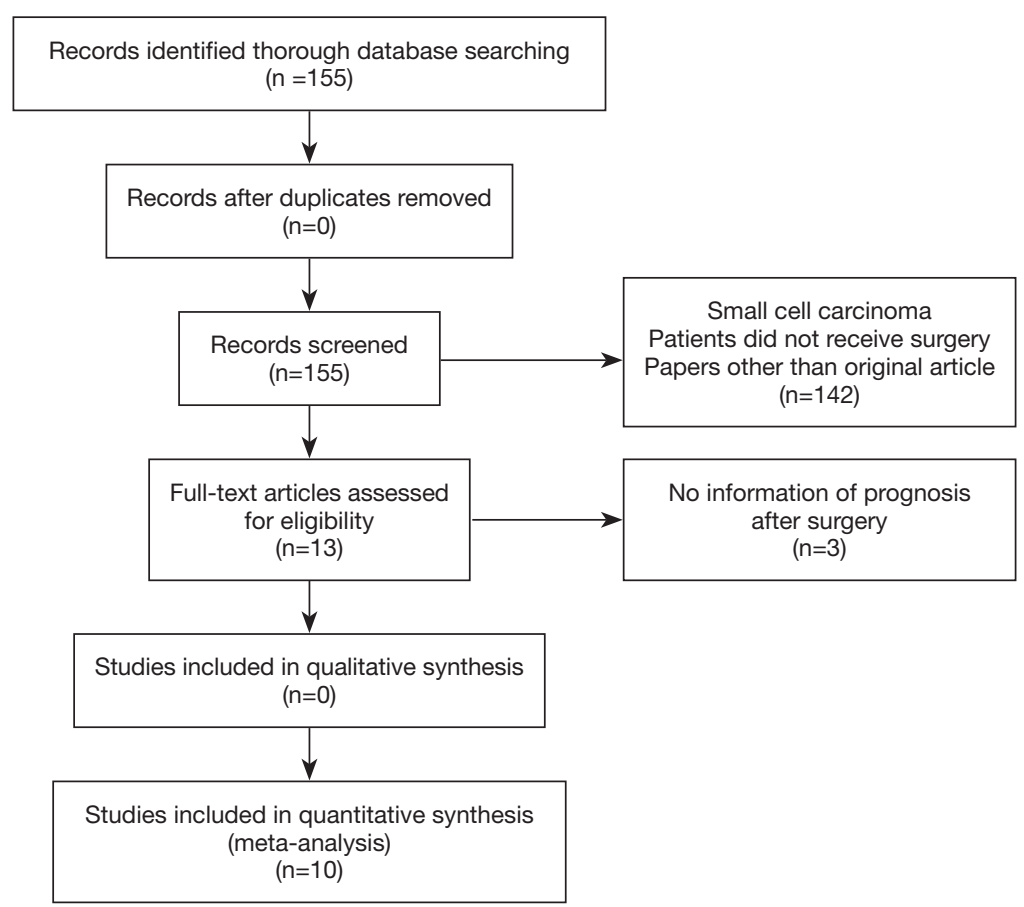

Figure 1 A flow chart describing the selection process of our study.

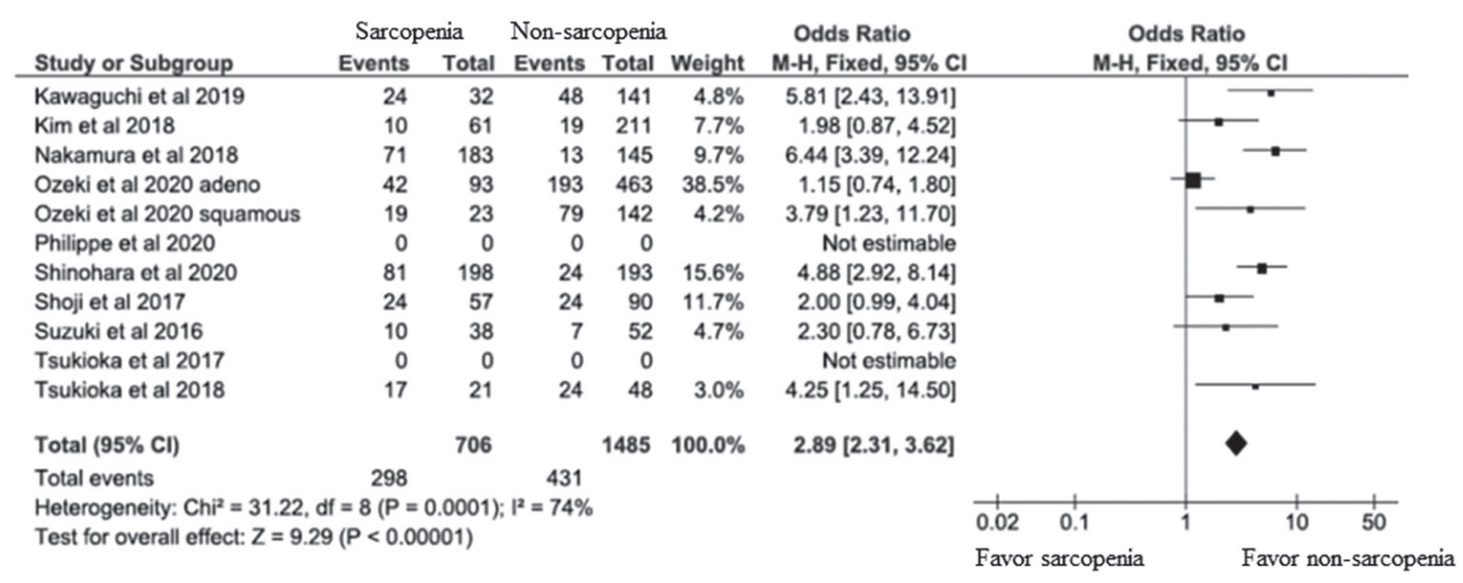

Figure 2 Meta-analysis of sarcopenia and overall survival. Forest plots of odds ratio for overall survivals of each study and pooled odds ratio.

pathological stages were mainly within 0 to 3 , twelve patients with stage 4 were included in two studies. We judged this had little influence on survival since these patients were in stage 4 because of oligometastases, and these cases were few (12 out of 2,643 cases). Many surgical procedures were lobectomies, but limited resections were also performed. With the use of the Newcastle-Ottawa Scale, one study scored nine stars, three studies scored eight stars, four studies scored seven stars and two studies scored six stars (Table 1).

\section{Sarcopenia predicts poor prognosis after surgery in patients with NSCLC}

Table 1 and Figures 2,3 show OS and DFS data. Of the ten studies, nine demonstrated that patients with sarcopenia had 


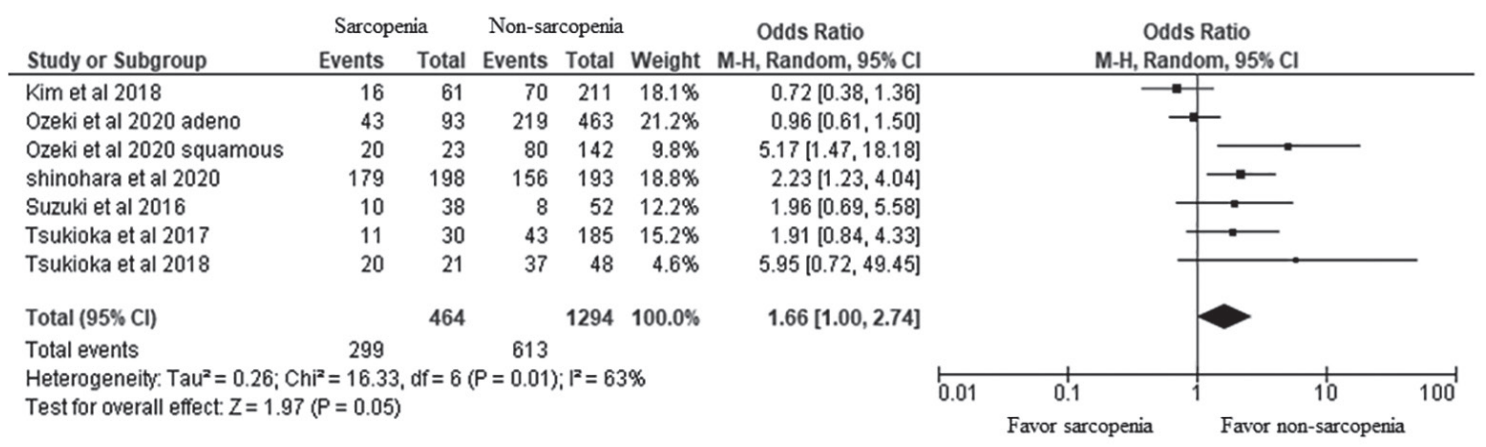

Figure 3 Meta-analysis of sarcopenia and disease-free survival. Forest plots of odds ratio for disease free survivals of each study and pooled odds ratio.

a significantly lower OS rate than those without sarcopenia. However, potential heterogeneities were observed in these studies. To decrease possible heterogeneities, we focused on studies of the same stage of NSCLC or single surgical procedures, or the corresponding histology. Three studies only focused on stage 1 non-small cell lung cancer, with a total of 452 patients. One study with 69 patients, exclusively focused on stage 3A NSCLC. These studies demonstrated that patients with sarcopenia have a lower 5 -year OS than those without sarcopenia. Two studies, with a total of 242 patients, only focused on a single surgical procedure, lobectomy. These studies also demonstrated that patients with sarcopenia had a lower OS than those without sarcopenia. One study showed OS dividing into adenocarcinoma and squamous cell carcinoma. They demonstrated that sarcopenia was associated with lower OS in squamous cell carcinoma patients. On the other hand, sarcopenia had no impact on the OS in adenocarcinoma patients. A total of 2,191 patients from nine studies were included in the meta-analysis, which showed worse OS in patients with sarcopenia than those without sarcopenia (odds ratio $3.07,95 \%$ CI: $2.45-3.85$; Figure 2 ). We could not include two studies $(10,16)$ in this meta-analysis because the number of patients with sarcopenia or 5 -year OS was not indicated.

As for DFS, of the six studies, three demonstrated that patients with sarcopenia had a significantly lower DFS rate than those without sarcopenia. In these three studies, one study focused on stage 3A NSCLC, and two studies reported several stages of NSCLC. Total of 1,758 patients from six studies were included in the meta-analysis and we observed a worse DFS in patients with sarcopenia compared to patients without sarcopenia (odds ratio $1.66,95 \% \mathrm{CI}$ :

\subsection{0-2.74; Figure 3).}

\section{Sarcopenia predicts postoperative complications in patients with NSCLC}

Postoperative in-hospital complications are shown in Table 2. Of seven studies, two studies demonstrated that sarcopenia was significantly associated with postoperative complications. Nakamura et al. reported that major postoperative complications (Clavien-Dindo grade $\geq 3$ ) occurred more frequently in patients with sarcopenia than those without sarcopenia $(\mathrm{P}=0.036)$. Kawaguchi et al. also reported that postoperative all complications were significantly higher in patients with sarcopenia than those without sarcopenia. The other four studies also showed that patients with sarcopenia tended to experience postoperative complications (although not statistically significant). A meta-analysis of the postoperative complications from six articles that included a total of 1,538 patients was performed. This revealed an increased risk of postoperative complications for patients with sarcopenia (odds ratio 1.86, 95\% CI: 1.42-2.44; Figure 4).

\section{Optimal diagnostic tool and cut off value for sarcopenia}

Sarcopenia was defined using: (I) a sum of skeletal muscles at L3 level normalized for height (L3MI, $\mathrm{cm}^{2} / \mathrm{m}^{2}$ ) in 5 studies; (II) the psoas muscle area at L3 level normalized for height (PMI, $\mathrm{cm}^{2} / \mathrm{m}^{2}$ ) in 4 studies; and (III) the total muscular mass normalized for height $\left(\mathrm{TMMi}, \mathrm{kg} / \mathrm{m}^{2}\right)$ in 1 study (Table 1). Muscle mass at the L3 level was often used as a diagnostic marker because it reflects the skeletal muscle mass of the whole body, and it is easy to calculate. The cut- 
Table 2 Study characteristics assessed on postoperative complications

\begin{tabular}{|c|c|c|c|c|c|}
\hline $\begin{array}{l}\text { Author, } \\
\text { publication year }\end{array}$ & Number of patients & Surgical procedure & $\begin{array}{l}\text { Diagnostic tool } \\
\text { of sarcopenia }\end{array}$ & Cut off value & Post-operative complications \\
\hline $\begin{array}{l}\text { Suzuki } \\
\text { et al., } 2016\end{array}$ & $\begin{array}{l}\text { 90-sarcopenia: } 38 \\
\text { non-sarcopenia: } 52\end{array}$ & $\begin{array}{l}\text { Lobectomy: NA; } \\
\text { segmentectomy: NA; } \\
\text { wedge resection: NA }\end{array}$ & L3MI $\left(\mathrm{cm}^{2}\right)$ & $\begin{array}{l}\text { Male: } 43.75 \mathrm{~cm}^{2} / \mathrm{m}^{2} \\
\text { female: } 41.10 \mathrm{~cm}^{2} / \mathrm{m}^{2}\end{array}$ & $\begin{array}{l}\text { Sarcopenia: } 29 \% \text {; } \\
\text { non-sarcopenia: } 21 \% \\
(P=0.39)\end{array}$ \\
\hline $\begin{array}{l}\text { Tsukioka } \\
\text { et al., } 2017\end{array}$ & $\begin{array}{l}215 \text { (male)-sarcopenia: } \\
\text { 30; non-sarcopenia: } 185\end{array}$ & $\begin{array}{l}\text { Lobectomy: NA; } \\
\text { segmentectomy: NA }\end{array}$ & L3MI $\left(\mathrm{cm}^{2}\right)$ & $\begin{array}{l}\text { Male: } 49 \mathrm{~cm}^{2} / \mathrm{m}^{2} \text {; } \\
\text { female: none }\end{array}$ & $\begin{array}{l}\text { Sarcopenia: } 28 \% \text {; } \\
\text { non-sarcopenia: } 19 \% \\
(P=0.340)\end{array}$ \\
\hline $\begin{array}{l}\text { Kim } \\
\text { et al., } 2018\end{array}$ & $\begin{array}{l}\text { 272-sarcopenia: } 61 \text {; } \\
\text { non-sarcopenia: } 211\end{array}$ & $\begin{array}{l}\text { Pneumonectomy: } 14 ; \\
\text { lobectomy: } 255 ; \\
\text { segmentectomy: } 3\end{array}$ & L3MI $\left(\mathrm{cm}^{2}\right)$ & $\begin{array}{l}\text { Male: } 55 \mathrm{~cm}^{2} / \mathrm{m}^{2} ; \\
\text { female: } 39 \mathrm{~cm}^{2} / \mathrm{m}^{2}\end{array}$ & $\begin{array}{l}\text { Sarcopenia: } 29.5 \% \text {; } \\
\text { non-sarcopenia: } 20.9 \% \\
(P=0.168)\end{array}$ \\
\hline $\begin{array}{l}\text { Nakamura } \\
\text { et al., } 2018\end{array}$ & $\begin{array}{l}\text { 328-sarcopenia: } 183 \text {; } \\
\text { non-sarcopenia: } 145\end{array}$ & $\begin{array}{l}\text { Lobectomy: 259; } \\
\text { limited resection: } 69\end{array}$ & $\mathrm{PMI}\left(\mathrm{cm}^{2} / \mathrm{m}^{2}\right)$ & $\begin{array}{l}\text { Male: } 6.36 \mathrm{~cm}^{2} / \mathrm{m}^{2} ; \\
\text { female: } 3.92 \mathrm{~cm}^{2} / \mathrm{m}^{2}\end{array}$ & $\begin{array}{l}\text { Sarcopenia: } 7 \% \text {; } \\
\text { non-sarcopenia: } 2 \%(P=0.036) \\
\text { (Clavian-Dindo grade } \geq 3 \text { ) }\end{array}$ \\
\hline $\begin{array}{l}\text { Kawaguchi } \\
\text { et al., } 2019\end{array}$ & $\begin{array}{l}173 \text { (over } 75 \text { years)- } \\
\text { sarcopenia: } 32 ; \\
\text { non-sarcopenia: } 141\end{array}$ & Lobectomy: 173 & $\mathrm{PMI}\left(\mathrm{cm}^{2} / \mathrm{m}^{2}\right)$ & $\begin{array}{l}\text { Male: } 3.70 \mathrm{~cm}^{2} / \mathrm{m}^{2} ; \\
\text { female: } 2.50 \mathrm{~cm}^{2} / \mathrm{m}^{2}\end{array}$ & $\begin{array}{l}\text { Sarcopenia: } 62.5 \% \text {; } \\
\text { non-sarcopenia: } 22.7 \% \\
(\mathrm{P}<0.001)\end{array}$ \\
\hline $\begin{array}{l}\text { Shinohara et al., } \\
2020\end{array}$ & $\begin{array}{l}\text { 391-sarcopenia: 198; } \\
\text { non-sarcopenia: } 193\end{array}$ & $\begin{array}{l}\text { Pneumonectomy: } 3 \text {; } \\
\text { lobectomy: } 312 ; \\
\text { limited resection: } 76\end{array}$ & $\mathrm{PMI}\left(\mathrm{cm}^{2} / \mathrm{m}^{2}\right)$ & $\begin{array}{l}\text { Male: } 6.36 \mathrm{~cm}^{2} / \mathrm{m}^{2} ; \\
\text { female: } 3.92 \mathrm{~cm}^{2} / \mathrm{m}^{2}\end{array}$ & $\begin{array}{l}\text { Sarcopenia: } 34.8 \% \text {; } \\
\text { non-sarcopenia: } 28.5 \% \\
(P=0.19)\end{array}$ \\
\hline
\end{tabular}

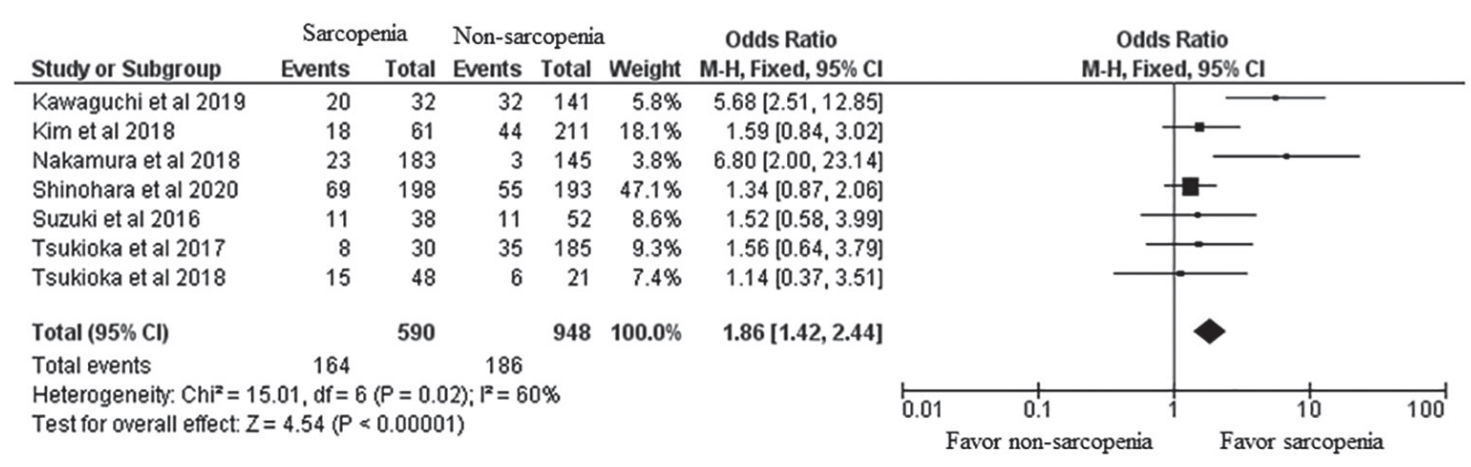

Figure 4 Meta-analysis of sarcopenia and postoperative complications. Forest plots of odds ratio for postoperative complications of each study and pooled odds ratio.

off value varied in studies. L3MI ranged from 43.75 to 55.0 in male patients and ranged from 38.5 to 41.1 in female patients. PMI ranged from 3.70 to 8.71 in male patients and ranged from 2.50 to 6.51 in female patients. The cutoff value of TMMi was $6.49 \mathrm{~kg} / \mathrm{m}^{2}$. For L3MI and PMI, the lower the cut-off value, the worse the prognosis was. The association of sarcopenia and postoperative complications was only seen in studies with low cut off levels for sarcopenia, or in studies with limited severe complications. As a result, L3MI, PMI, TMMi were all optimal diagnostic tools for prognosis and tended to become a worse prognosis when the cut-off values were low. Furthermore, PMI might 
Table 3 The association between sarcopenia and smoking history

\begin{tabular}{lccc}
\hline Author, publication year & Sarcopenia, ever/never smoker & Non-sarcopenia, ever/never smoker & P value \\
\hline Suzuki et al., 2016 & $22(57.9 \%) / 16(39.5 \%)$ & $16(30.8 \%) / 36(69.2 \%)$ & 0.78 \\
Kim et al., 2018 & $46(75.4 \%) / 15(24.6 \%)$ & $113(53.6 \%) / 98(46.4 \%)$ \\
Nakamura et al., 2018 & $127(69.4 \%) / 56(30.6 \%)$ & $72(50.1) / 73(49.9)$ & 0.003 \\
Shinohara et al., 2020 & $172(89.9 \%) / 26(10.1 \%)$ & $134(69.4 \%) / 59(30.6 \%)$ & $16(5.3 \%) / 288(94.7 \%)$ \\
Philippe et al., 2020 & $285(93.6 \%) / 19(6.4 \%)$ & 0.001 & 0.91 \\
\hline
\end{tabular}

predict postoperative complications, when the cut-off value was low, or complications limited severity.

\section{The association between sarcopenia and smoking history}

Of the ten studies, five reported the smoking history of patients (Table 3). Three studies demonstrated that sarcopenia was significantly associated with smoking history, which included an ever smoker and a current smoker.

\section{Discussion}

\section{Sarcopenia and prognosis}

In this meta-analysis, we found significantly poor postoperative OS and DFS in lung cancer patients with sarcopenia. In patients with other types of malignancies, sarcopenia also predicted poor survival (3-5). There are four reasons for the poor prognosis after surgery in patients with sarcopenia. First, sarcopenia itself is a poor prognosis. Even if the cancer is completely in remission, the loss of muscle mass and strength continues, resulting in physical disability and death (1). Second, postoperative complications negatively affect prognosis. Patients with sarcopenia tend to have postoperative complications. The incidence of these complications may strongly predict a poor prognosis because physical ability is decreased by complications, resulting in poor responses to treatment for not only cancer but also other diseases (18). Third, a tumor occurring in sarcopenia patients has a more malignant potential than that occurring in patients without sarcopenia. As a result, even if the pathological stages were the same in both sarcopenia and non-sarcopenia patients, the tumor recurrence will be frequently observed in sarcopenia patients (11). Finally, the most interesting theory is that muscles have a potential tumor inhibitory effect via the help of myokines. Skeletal muscles have recently been identified as secretory organs, that produce myokines, which suppresses the growth of cancer cells and are involved in the control of immune cells $(19,20)$. For example, muscle-derived myokines, such as Oncostatin $M$, Irisin, and SPARC inhibit the growth of mammary and colonic cancer cell in vitro $(21,22)$. In a study using mouse models, wheel running exercises induced muscles to release IL-6, and this muscle-derived IL-6 mobilize natural killer cells to attack tumors and reduces tumor growth (23). Furthermore, exercise-induced catecholamines activate the Hippo Tumor Suppressor Pathway to reduce tumor growth (24). Ozeki et al. reported that high volume muscle mass group prolonged DFS after surgery in patients with squamous cell carcinoma, which might indicate the tumor inhibitory effect via myokines (7).

\section{Sarcopenia and postoperative complications}

Our meta-analysis showed an increased risk of postoperative complications for patients with sarcopenia. Reports on other cancers also indicate an association between sarcopenia and postoperative complications. For example, gastrointestinal cancer $(5,25)$, hepatopancreaticobiliary cancer (5), renal cancer (26) showed a significant increase in postoperative complications. Muscle-derived IL-6 inhibits TNF production and stimulates the production of the anti-inflammatory cytokines IL-1 ra and IL-10 (20). Therefore, patients with sarcopenia experience a high inflammatory response after surgery due to low levels of anti-inflammatory cytokines, leading to the development of postoperative complications (27).

Based on these results, sarcopenia can be used to identify patients at a high risk of postoperative complications, and it requires intensive care after surgery. Furthermore, surgeons can consider a less-invasive treatment such as limited resection or stereotactic irradiation for patients with 
Table 4 Proposed diagnostic tool and cut-off values of sarcopenia

\begin{tabular}{lcc}
\hline Outcome & Proposed diagnostic tool of sarcopenia & Proposed cut off value \\
\hline Prognosis & $\mathrm{PMI}\left(\mathrm{cm}^{2} / \mathrm{m}^{2}\right)$ & Male: $6.36 \mathrm{~cm}^{2} / \mathrm{m}^{2} ; \mathrm{female:} 3.92 \mathrm{~cm}^{2} / \mathrm{m}^{2}$ \\
Post-operative complication & $\mathrm{PMI}\left(\mathrm{cm}^{2} / \mathrm{m}^{2}\right)$ & Male: $3.70 \mathrm{~cm}^{2} / \mathrm{m}^{2} ; \mathrm{female:} 2.50 \mathrm{~cm}^{2} / \mathrm{m}^{2}$ \\
\hline
\end{tabular}

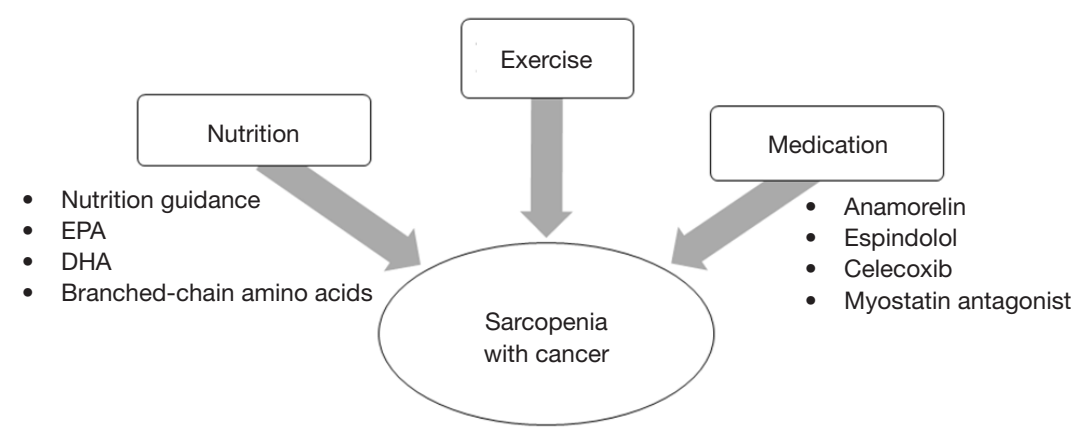

Figure 5 Therapeutic approaches for sarcopenia with cancer.

sarcopenia (27).

\section{Optimal diagnosis of sarcopenia}

We reviewed the diagnostic tools for sarcopenia. The European Working Group on Sarcopenia proposed the following diagnostic criteria; the presence of low gait speed $(<0.8 \mathrm{~m} / \mathrm{s}$ in 4 -minute walking test), decreased grip strength ( $<30 \mathrm{~kg}$ for men, $<20 \mathrm{~kg}$ for women), and low muscle mass (1). However, these examinations are complex to perform. In addition, patients who meet these criteria rarely become candidates for surgery because of their poor performance statuses. Clinicians need a brief and optimal criterion for sarcopenia in order to predict postoperative outcomes for NSCLC patients. In our review, five studies used L3MI, four studies used PMI, and 1 study used TMMi as diagnostic tools for sarcopenia. When considering both the predictability of postoperative outcomes and ease of assessment, PMI may be feasible. Nakamura et al. (8), and Shinohara et al. (15) used $6.36 \mathrm{~cm}^{2} / \mathrm{m}^{2}$ as the cut-off value for sarcopenia in male patients, and $3.92 \mathrm{~cm}^{2} / \mathrm{m}^{2}$ in female patients, which were defined as $<2$ SD below the mean PMI of healthy individuals (28). Ozeki et al. (7) used $8.71 \mathrm{~cm}^{2} / \mathrm{m}^{2}$ in male patients and $6.51 \mathrm{~cm}^{2} / \mathrm{m}^{2}$ in female patients with adenocarcinomas, and $7.65 \mathrm{~cm}^{2} / \mathrm{m}^{2}$ in male patients and $6.02 \mathrm{~cm}^{2} / \mathrm{m}^{2}$ in female patients with squamous cell carcinoma. Kawaguchi et al. (14) used $3.70 \mathrm{~cm}^{2} / \mathrm{m}^{2}$ in male patients and $2.50 \mathrm{~cm}^{2} / \mathrm{m}^{2}$ in female patients; this was defined based on the point of a rapid rise in postoperative complications rate.

Based on these results, the optimal cut off values of PMI in predicting prognosis are $6.36 \mathrm{~cm}^{2} / \mathrm{m}^{2}$ in male patients and $3.92 \mathrm{~cm}^{2} / \mathrm{m}^{2}$ in female patients, and those used in predicting postoperative complications are $3.70 \mathrm{~cm}^{2} / \mathrm{m}^{2}$ in male patients and $2.50 \mathrm{~cm}^{2} / \mathrm{m}^{2}$ in female patients (Table 4).

\section{Therapeutic approach for sarcopenia}

It is unclear whether therapeutic intervention for sarcopenia prevents postoperative complications or improves OS and DFS (29). However, we believe that sarcopenia can become a treatment target when trying to improve outcomes in NSCLC patients who have undergone surgery. Treatment for sarcopenia consists of three approaches: exercise, nutrition, and medication (Figure 5).

Physical inactivity increases the risk of development of colon (30) and breast cancers (31). Some studies in patients with breast cancer have shown the association between exercise after cancer diagnosis with improved survival $(32,33)$. For example, Chen et al., demonstrated that patients who engaged in exercise regularly during the first six months after diagnosis had significantly higher OS and DFS (HR: 0.62, HR: 0.39, respectively) than those who did not exercise (32). However, it is challenging to define "exercise" because the type and strength of exercise in studies vary, for example walking, gymnastics, body building and traditional Chinese exercises. Some reports recommend about 

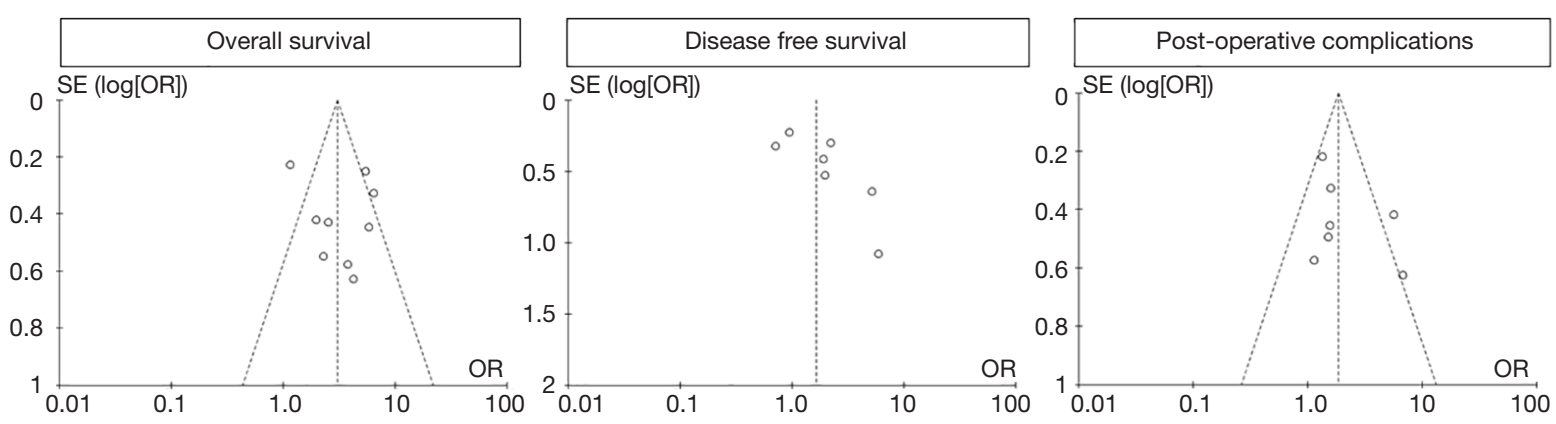

Figure 6 Funnel plot of the included studies for the analysis of OS, DFS, and postoperative complications. OS, overall survival; DFS, disease-free survival.

2.5 hours each week of moderate-intensity physical activity, like walking, as exercise $(32,33)$; this may be reasonable to perform routinely, and it demonstrated an improving prognosis.

Nutrition is also crucial in the treatment of sarcopenia; however, there are few reports on nutritional interventions. In lung cancer patients, sarcopenia was significantly associated with an inadequate intake of protein (34). Eicosapentaenoic acid (EPA), docosahexaenoic acid (DHA), and (n-3) fatty acids from fish oil have immune-modulating effects and may improve nutritional status in cancer patients. These dietary supplements contribute to weight maintenance and improvement of walking function (35). Two feasibility studies evaluated the multimodal therapy of exercise and nutrition. In the Pre-MENAC research, the treatment arm consisted of celecoxib $300 \mathrm{mg}$ once daily, EPA 2 g/day, training, and nutrition guidance for patients with lung and pancreatic cancer. Patients in the treatment arm increased in weight more than those in the control arm; however, muscle mass was not different between the two groups (36). In the MEXTAC study, supplements rich in branched-chain amino acids, nutrition guidance, and exercise were given to elderly patients with lung cancer, which showed proper compliance and safety (37). These studies are now in phases 3 and 2, respectively.

Drug therapy can also be used to treat sarcopenia. Anamorelin is a selective ghrelin receptor agonist, which has anabolic and appetite-enhancing activities. Anamorelin significantly increased lean body mass and improved appetite and nutritional state in patients with advanced lung cancer (38). Espindolol has three pharmacological targets: blockade of non-selective $\beta$ receptors (thus reducing catabolism), antagonism of central 5-HT1 a receptors (potentially reducing fatigue and thermogenesis), and partial agonism of $\beta 2$ receptors (increasing anabolism). Espindolol significantly reversed weight loss, and improves lean body mass in sarcopenic patients with advanced colorectal and lung cancer (39). Myostatin, which inhibits muscle hypertrophy, may become the target in the treatment of sarcopenia (20). Administration of a myostatin antagonist in mice with lung cancer resulted in improvement in body muscle weight and agility. Furthermore, tumor volume decreased in mice treated with myostatin antagonist compared to control mice (40).

Several studies have indicated that smoking may contribute to the development of sarcopenia (41). In our study, three studies showed the number of patients with smoking history were larger in sarcopenia than nonsarcopenia. So, quitting smoking may become one of the therapies for sarcopenia.

These above-described interventions focused on patients with advanced cancer. However, we believe that interventions for sarcopenia with a resectable lung cancer also improve their prognosis. Presently, we propose exercise and an improvement of the nutritional status. Muscle mass can improve with exercise and the administration of nutrients (42), which can improve their prognosis.

\section{Limitations}

Several limitations existed in this study. Due to the observational design of the included studies, the respective meta-analysis may be affected by the biases found in the original data. Especially we should be careful for three biases. One is a publication bias, which were tested by funnel plot for the analysis of OS, DFS and postoperative complications, and these plots had a symmetrical appearance (Figure 6). Second, there was heterogeneity in 
the assessment or definition of sarcopenia. In addition, the tumor stage and the number of patients involved in the analysis of the prognosis in each article was varied. Third, our extracted papers are biased toward the Asian countries (Japan: 8, Korea: 1, and France: 1).

In conclusion, the results of this systematic review and meta-analysis demonstrated that resectable NSCLC patients with sarcopenia had significantly worse OS, DFS, and frequent development of postoperative complications than that of patients without sarcopenia. To diagnose sarcopenia, CT-based skeletal muscle measurements, like PMI, were useful. In the future, it is necessary to explore the mechanisms of sarcopenia and the roles of optimal intervention, such as exercise, nutrition, and drug therapy in its management.

\section{Acknowledgments}

Funding: None.

\section{Footnote}

Reporting Checklist: The authors have completed the PRISMA reporting checklist. Available at http://dx.doi. org/10.21037/jtd-20-3072

Peer Review File: Available at http://dx.doi.org/10.21037/jtd20-3072

Conflicts of Interest: All authors have completed the ICMJE uniform disclosure form (available at http://dx.doi. org/10.21037/jtd-20-3072). The authors have no conflicts of interest to declare.

Ethical Statement: The authors are accountable for all aspects of the work in ensuring that questions related to the accuracy or integrity of any part of the work are appropriately investigated and resolved. This study did not include experimentation on human or animal subjects; thus, institutional review board approval was not required.

Open Access Statement: This is an Open Access article distributed in accordance with the Creative Commons Attribution-NonCommercial-NoDerivs 4.0 International License (CC BY-NC-ND 4.0), which permits the noncommercial replication and distribution of the article with the strict proviso that no changes or edits are made and the original work is properly cited (including links to both the formal publication through the relevant DOI and the license). See: https://creativecommons.org/licenses/by-nc-nd/4.0/.

\section{References}

1. Cruz-Jentoft AJ, Baeyens JP, Bauer JM, et al. Sarcopenia: European consensus on definition and diagnosis: Report of the European Working Group on Sarcopenia in Older People. Age Ageing 2010;39:412-23.

2. Fearon KC. Cancer cachexia and fat-muscle physiology. N Engl J Med 2011;365:565-7.

3. Harimoto N, Yoshizumi T, Shimokawa M, et al. Sarcopenia is a poor prognostic factor following hepatic resection in patients aged 70 years and older with hepatocellular carcinoma. Hepatol Res 2016;46:1247-55.

4. Villaseñor A, Ballard-Barbash R, Baumgartner K, et al. Prevalence and prognostic effect of sarcopenia in breast cancer survivors: the HEAL Study. J Cancer Surviv 2012;6:398-406.

5. Levolger S, van Vugt JL, de Bruin RW, et al. Systematic review of sarcopenia in patients operated on for gastrointestinal and hepatopancreatobiliary malignancies. Br J Surg 2015;102:1448-58.

6. Stene GB, Helbostad JL, Amundsen T, et al. Changes in skeletal muscle mass during palliative chemotherapy in patients with advanced lung cancer. Acta Oncol 2015;54:340-8.

7. Ozeki N, Kawaguchi K, Fukui T, et al. Psoas muscle mass in patients undergoing lung cancer surgery: a prognostic difference between squamous cell carcinoma and adenocarcinoma. Int J Clin Oncol 2020;18:020-01624.

8. Nakamura R, Inage $Y$, Tobita R, et al. Sarcopenia in Resected NSCLC: Effect on Postoperative Outcomes. J Thorac Oncol 2018;13:895-903.

9. Suzuki Y, Okamoto T, Fujishita T, et al. Clinical implications of sarcopenia in patients undergoing complete resection for early non-small cell lung cancer. Lung Cancer 2016;101:92-7.

10. Tsukioka T, Nishiyama N, Izumi N, et al. Sarcopenia is a novel poor prognostic factor in male patients with pathological Stage I non-small cell lung cancer. Jpn J Clin Oncol 2017;47:363-8.

11. Tsukioka T, Izumi N, Mizuguchi S, et al. Positive correlation between sarcopenia and elevation of neutrophil/lymphocyte ratio in pathological stage IIIA (N2-positive) non-small cell lung cancer patients. Gen Thorac Cardiovasc Surg 2018;66:716-22.

12. Shoji F, Matsubara T, Kozuma Y, et al. Relationship Between 
Preoperative Sarcopenia Status and Immuno-nutritional Parameters in Patients with Early-stage Non-small Cell Lung Cancer. Anticancer Res 2017;37:6997-7003.

13. Kim EY, Lee HY, Kim KW, et al. Preoperative Computed Tomography-Determined Sarcopenia and Postoperative Outcome After Surgery for Non-Small Cell Lung Cancer. Scand J Surg 2018;107:244-51.

14. Kawaguchi Y, Hanaoka J, Ohshio Y, et al. Sarcopenia predicts poor postoperative outcome in elderly patients with lung cancer. Gen Thorac Cardiovasc Surg 2019;67:949-54.

15. Shinohara S, Otsuki R, Kobayashi K, et al. Impact of Sarcopenia on Surgical Outcomes in Non-small Cell Lung Cancer. Ann Surg Oncol 2020;22:020-08224.

16. Icard P, Schussler O, Loi M, et al. Pre-Disease and PreSurgery BMI, Weight Loss and Sarcopenia Impact Survival of Resected Lung Cancer Independently of Tumor Stage. Cancers (Basel) 2020;12:266.

17. Deng HY, Hou L, Zha P, et al. Sarcopenia is an independent unfavorable prognostic factor of non-small cell lung cancer after surgical resection: A comprehensive systematic review and meta-analysis. Eur J Surg Oncol 2019;45:728-35.

18. Kawaguchi Y, Hanaoka J, Oshio Y, et al. Decrease in performance status after lobectomy mean poor prognosis in elderly lung cancer patients. J Thorac Dis 2017;9:1525-30.

19. Pedersen BK, Febbraio MA. Muscles, exercise and obesity: skeletal muscle as a secretory organ. Nat Rev Endocrinol 2012;8:457-65.

20. Benatti FB, Pedersen BK. Exercise as an anti-inflammatory therapy for rheumatic diseases-myokine regulation. Nat Rev Rheumatol 2015;11:86-97.

21. Hojman P, Dethlefsen C, Brandt C, et al. Exercise-induced muscle-derived cytokines inhibit mammary cancer cell growth. Am J Physiol Endocrinol Metab 2011;301:E504.

22. Aoi W, Naito Y, Takagi T, et al. A novel myokine, secreted protein acidic and rich in cysteine (SPARC), suppresses colon tumorigenesis via regular exercise. Gut 2013;62:882-9.

23. Lucia A, Ramirez M. Muscling In on Cancer. N Engl J Med 2016;375:892-4.

24. Dethlefsen C, Hansen LS, Lillelund C, et al. ExerciseInduced Catecholamines Activate the Hippo Tumor Suppressor Pathway to Reduce Risks of Breast Cancer Development. Cancer Res 2017;77:4894-904.

25. Simonsen C, de Heer P, Bjerre ED, et al. Sarcopenia and Postoperative Complication Risk in Gastrointestinal Surgical Oncology: A Meta-analysis. Ann Surg 2018;268:58-69.
26. Peyton CC, Heavner MG, Rague JT, et al. Does Sarcopenia Impact Complications and Overall Survival in Patients Undergoing Radical Nephrectomy for Stage III and IV Kidney Cancer? J Endourol 2016;30:229-36.

27. Reisinger KW, Derikx JP, van Vugt JL, et al. Sarcopenia is associated with an increased inflammatory response to surgery in colorectal cancer. Clin Nutr 2016;35:924-7.

28. Hamaguchi Y, Kaido T, Okumura S, et al. Proposal for new diagnostic criteria for low skeletal muscle mass based on computed tomography imaging in Asian adults. Nutrition 2016;32:1200-5.

29. Christensen JF, Jones LW, Andersen JL, et al. Muscle dysfunction in cancer patients. Ann Oncol 2014;25:947-58.

30. Papadimitriou N, Dimou N, Tsilidis KK, et al. Physical activity and risks of breast and colorectal cancer: a Mendelian randomisation analysis. Nat Commun 2020;11:020-14389.

31. Monninkhof EM, Elias SG, Vlems FA, et al. Physical activity and breast cancer: a systematic review. Epidemiology 2007;18:137-57.

32. Chen X, Lu W, Zheng W, et al. Exercise after diagnosis of breast cancer in association with survival. Cancer Prev Res (Phila) 2011;4:1409-18.

33. Irwin ML, Smith AW, McTiernan A, et al. Influence of pre- and postdiagnosis physical activity on mortality in breast cancer survivors: the health, eating, activity, and lifestyle study. J Clin Oncol 2008;26:3958-64.

34. Kim EY, Kim K, Kim YS, et al. Prevalence of and Factors Associated with Sarcopenia in Korean Cancer Survivors: Based on Data Obtained by the Korea National Health and Nutrition Examination Survey (KNHANES) 20082011. Nutr Cancer 2017;69:394-401.

35. van der Meij BS, Langius JA, Smit EF, et al. Oral nutritional supplements containing (n-3) polyunsaturated fatty acids affect the nutritional status of patients with stage III non-small cell lung cancer during multimodality treatment. J Nutr 2010;140:1774-80.

36. Solheim TS, Laird BJA, Balstad TR, et al. A randomized phase II feasibility trial of a multimodal intervention for the management of cachexia in lung and pancreatic cancer. J Cachexia Sarcopenia Muscle 2017;8:778-88.

37. Naito T, Mitsunaga S, Miura S, et al. Feasibility of early multimodal interventions for elderly patients with advanced pancreatic and non-small-cell lung cancer. J Cachexia Sarcopenia Muscle 2019;10:73-83.

38. Katakami N, Uchino J, Yokoyama T, et al. Anamorelin (ONO-7643) for the treatment of patients with non-small cell lung cancer and cachexia: Results from a randomized, 
double-blind, placebo-controlled, multicenter study of Japanese patients (ONO-7643-04). Cancer 2018;124:606-16.

39. Stewart Coats AJ, Ho GF, Prabhash K, et al. Espindolol for the treatment and prevention of cachexia in patients with stage III/IV non-small cell lung cancer or colorectal cancer: a randomized, double-blind, placebo-controlled, international multicentre phase II study (the ACT-ONE trial). J Cachexia Sarcopenia Muscle 2016;7:355-65.

40. Busquets S, Toledo M, Orpi M, et al. Myostatin blockage using actRIIB antagonism in mice bearing the Lewis lung

Cite this article as: Kawaguchi $\mathrm{Y}$, Hanaoka J, Ohshio Y, Okamoto K, Kaku R, Hayashi K, Shiratori T, Akazawa A. Does sarcopenia affect postoperative short- and long-term outcomes in patients with lung cancer?-a systematic review and metaanalysis. J Thorac Dis 2021;13(3):1358-1369. doi: 10.21037/jtd-203072 carcinoma results in the improvement of muscle wasting and physical performance. J Cachexia Sarcopenia Muscle 2012;3:37-43.

41. Steffl M, Bohannon RW, Petr M, et al. Relation between cigarette smoking and sarcopenia: meta-analysis. Physiol Res 2015;64:419-26.

42. Landi F, Marzetti E, Martone AM, et al. Exercise as a remedy for sarcopenia. Curr Opin Clin Nutr Metab Care 2014;17:25-31. 